pISSN: 2527-5267 eISSN: 2621-7708

Vol. 5 No. 1 (2020): 6-10

\title{
ANALISIS KANDUNGAN BORAKS PADA JAJANAN ANAK DI SEKITAR SDN 18 DAN 20 KOTA PEKANBARU
}

\author{
Harni Sepriyani ${ }^{1}$, Rosa Devitria ${ }^{1}$ \\ ${ }^{1}$ Analis Kesehatan, Fakultas Kedokteran dan Ilmu Kesehatan, Universitas Abdurrab \\ Surat elektronik: \\ ${ }^{1}$ Analis Kesehatan, Fakultas Kedokteran dan Ilmu Kesehatan, Universitas Abdurrab \\ Jalan Riau Ujung No. 73 Kota Pekanbaru \\ Surat elektronik: harni.sepriyani@universitas.ac.id
}

\begin{abstract}
ABSTRAK
Jajanan yang dijual di sekitar lingkungan menjadi kekhawatiran masyarakat khususnya orang tua siswa. Jajanan tersebut dikhawatirkan adanya penambahan zat makanan yang berbahaya, yaitu zat pengawet makanan. Salah satu zat pengawet makanan yang sering digunakan adalah natrium tetraborat. Natrium tetraborat lebih dikenal dengan nama boraks. Menurut Peraturan Menteri Kesehatan Republik Indonesia No. 1168/Menkes/Per/X/1999, boraks dinyatakan dilarang digunakan sebagai bahan tambahan makanan, tetapi masih banyak bentuk penyalahgunaan dari zat tersebut. Tujuan penelitian ini adalah untuk mengetahui kandungan boraks yang terdapat pada jajanan yang dijual sekitar SDN 18 dan 20 Kota Pekanbaru. Berdasarkan uji nyala yang telah dilakukan, dari 5 sampel terdapat 2 sampel yang positif mengandung boraks. Sampel positif boraks yaitu somai ikan dan martabak mini. Kandungan boraks pada sampel makanan somai ikan sebesar 2,2356 ppm. Kandungan boraks pada sampel makanan martabak mini sebesar 3,2272 ppm.
\end{abstract}

Kata kunci: Jajanan, boraks, uji nyala, spektrofotometer Uv-Vis .

\section{ABSTRACT}

Street snack which sold around the elementary school was to be concern of parent. It is feared that the addition of dangerous food substances, it is food preservatives. One of preservatives food is sodium tetraborate. Sodium tetraborate is better known as borax. According to the Regulation of the Minister of Health of the Republic of Indonesia No. 1168 / Menkes / Per / X / 1999, borax is declared prohibited from being used as food additives, but there are still many forms of abuse of these substances. The purpose of this study was to determine the content of borax contained in snacks sold around SDN 18 and 20 Pekanbaru City. Based on the flame test that has been done, from 5 samples there were 2 samples that were positive containing borax. Borax positive samples were fish somai and mini martabak. Borax content in fish somai food samples was $2.2356 \mathrm{ppm}$. The content of borax in mini martabak food samples was $3.2272 \mathrm{ppm}$.

Keywords: Street food, borax, flame test, spectrophotometer Uv-Vis

\section{PENDAHULUAN}

Jajanan sangat banyak dijual di sekitar lingkungan sekolah karena adanya kebiasaan siswa untuk belanja dan mengkonsumsi makanan. Siswa-siswa di Sekolah Dasar belum menyadari bahaya yang terdapat dalam jajanan yang mereka makan. Mereka tertarik dengan jajanan yang dijual karena variasi makanan, bentuk dan warna yang menarik, rasa yang menggugah selera, dan harga yang terjangkau. Berbagai jenis makanan menjadi jajanan sehari-hari siswa di sekolah, namun sebagian besar jajanan tersebut kurang memenuhi standar gizi dan keamanan pangan (Sultan., dkk, 2013). Keamanan pangan telah diamanatkan dalam Peraturan Pemerintah no. 28 tahun 2004. Keamanan pangan adalah kondisi dan upaya yang diperlukan untuk mencegah pangan dari kemungkinan cemaran secara biologis, kimia dan benda lain yang dapat mengganggu, merugikan dan 
membahayakan kesehatan manusia (Permenkes, 2004).

Rendahnya tingkat keamanan Pangan Jajanan Anak Sekolah (PJAS) masih menjadi permasalahan. Data pengawasan PJAS yang dilakukan Badan Pengawasan Obat dan Makanan (BPOM) RI Direktorat Inspeksi dan Sertifikasi Pangan bersama 26 Balai Besar/Balai POM di seluruh Indonesia pada tahun 2007, menunjukkan bahwa 45\% PJAS tidak memenuhi syarat karena mengandung bahan kimia berbahaya seperti formalin, boraks, rhodamin, dan mengandung Bahan Tambahan Pangan (BTP), seperti siklamat dan benzoat yang melebihi batas aman, serta adanya cemaran mikrobiologi. Kondisi makanan dan minuman yang tidak sehat, sangat merugikan karena anak-anak dapat terinfeksi, sakit atau keracunan. Bahan Tambahan Pangan (BTP) sudah digunakan secara umum oleh masyarakat termasuk dalam pembuatan jajanan (Sultan., dkk, 2013).

Larangan penggunaan boraks pada pangan juga diperkuat dengan Permenkes RI No.1168/Menkes/Per/X/1999, tentang bahan tambahan makanan bahwa natrium tetraborat yang lebih dikenal dengan nama boraks digolongkan dalam bahan tambahan yang dilarang digunakan dalam makanan, tetapi pada kenyataannya masih banyak bentuk penyalahgunaan dari zat tersebut (Tubagus., dkk, 2013). Efek negatif yang ditimbulkan akibat mengkonsumsi makanan yang mengandung boraks dapat berlangsung dalam waktu yang lama meskipun digunakan dalam jumlah sedikit. Boraks jika masuk ke dalam tubuh dapat mengakibatkan efek pada susunan syaraf pusat, ginjal, dan hati. Dosis fatal untuk dewasa sebesar 15 - 20 gram dan untuk anakanak sebesar 3-6 gram (Tubagus., dkk, 2013).

Pada tahun 2002, masyarakat dikejutkan oleh adanya penelitian dari BPOM yang menemukan adanya kandungan zat pengawet berbahaya seperti boraks dan formalin dalam bahan makanan jajanan yang dijual di sekolah, seperti bakso, mie basah, dan ikan asin. Penelitian di Kota Palembang menunjukkan bahwa dari sejumlah sampel yang diteliti, persentase sampel yang mengandung boraks adalah mie basah sebanyak $72 \%$, bakso sebanyak 70\%, dan empek-empek sebanyak 35 $\%$. Hasil analisis sampel jajanan oleh Badan Pengawas Obat dan Makanan antara Februari 2001 hingga Mei 2003, didapatkan bahwa dari 315 sampel, 155 (49\%) sampel mengandung rhodamin B, dari 1222 sampel, 129 (11\%) sampel mengandung boraks, dan dari 242 sampel, $80 \quad(33 \%)$ sampel mengandung formalin (Hidayat dan Muharrami, 2014).

Penelitian yang dilakukan di Kota Medan didapati adanya kandungan boraks pada jajanan bakso, bahwa $80 \%$ dari sampel yang diperiksa ternyata mengandung boraks. Kadar boraks yang ditemukan berkisar antara $0,08-0,29 \%$ dari berbagai lokasi yang diteliti (Tubagus., dkk, 2013). Berdasarkan hal tersebut, akan dilakukan analisis boraks pada jajanan anak yang dijual di sekitar SDN 18 dan SDN 20 Kota Pekanbaru.

\section{METODE}

Alat-alat yang digunakan dalam penelitian ini yaitu alat-alat gelas, lumpang dan alu, kertas saring, timbangan analitik, oven, spatula, cawan porselin, tanur, Spektrofotomerter UV-Vis. Bahan yang digunakan dalam penelitian secara kualitatif adalah asam sulfat pekat, metanol, akuades, kurkumin, etanol 96\%, dan natrium tetraborat deka hidrat.

\section{Preparasi sampel}

Sampel jajanan yang telah dihaluskan masing-masing ditimbang sebanyak 10 gram di dalam cawan porselen, lalu dikeringkan di oven pada suhu $60^{\circ} \mathrm{C}$ hingga benar-benar kering. Sampel selanjutnya diabukan dalam tanur pada suhu $600^{\circ} \mathrm{C}$ selama 8 jam. Abu kemudian dikeluarkan dari tanur dan dinginkan. Kemudian tambahkan $3 \mathrm{~mL}$ akuades panas, sambil diaduk dengan batang pengaduk, saring dengan kertas saring kemudian ditambahkan akuades hingga tanda batas, dan homogenkan larutan tersebut (Triastuti., dkk, 2013).

\section{Uji nyala api}

Nyala api dilakukan dengan penambahan $1-2$ tetes asam sulfat pekat dan $5-6$ tetes metanol pada sampel yang telah diabukan sebanyak 0,5 gr, natrium tetraborat (pembanding), dan natrium tetraborat + sampel 
(kontrol) kemudian dibakar. Bila timbul nyala hijau maka menandakan positif boraks. (Triastuti., dkk, 2013).

\section{Uji kuantitatif dengan Spektrofotometri UV-Vis}

Sampel dipipet sebanyak $1 \mathrm{~mL}$ lalu dimasukan ke dalam cawan porselin dan tambahkan $4 \mathrm{~mL}$ reagen kurkumin kemudian dipanaskan pada suhu $\pm 58^{\circ} \mathrm{C}$ selama 80 menit, hingga terbentuk endapan kuning kemerahan lalu ditambahkan $10 \mathrm{~mL}$ etanol $96 \%$ sampai terbentuk residu lalu dan masukkan ke dalam labu ukur $25 \mathrm{~mL}$ dan tambahkan etanol $96 \%$ sampai tanda batas. Absorbansi larutan menggunakan Spektrofotometer UV-Vis pada panjang gelombang $541 \mathrm{~nm}$.

\section{HASIL DAN PEMBAHASAN}

Analisis kandungan boraks pada jajanan anak yang dijual di sekitar SDN 18 dan SDN 20 Kota Pekanbaru dilakukan pada sampel martabak mini, mie goreng, martabak kering, somai ikan, dan kentang bulat. Pada setiap sampel dilakukan uji nyala terlebih dahulu dan dilanjutkan uji menggonakan spektrofotometer Uv-Vis. Hasil uji nyala dapat dilihat pada tabel 1 .

Tabel 1. Hasil Penelitian Uji Kualitatif Metode Uji Nyala

\begin{tabular}{cccc}
\hline No & Sampel & Uji Nyala & Hasil \\
\hline 1. & Martabak mini & Nyala hijau & + \\
2. & Mie goreng & Nyala oren kemerahan & - \\
3. & Martabak Kering & Nyala oren kemerahan & - \\
4. & Somai ikan & Nyala hijau & + \\
5. & Kentang bulat & Nyala oren kemerahan & - \\
6. & Pembanding & Nyala hijau & + \\
7. & Kontrol & Nyala hijau & + \\
\hline
\end{tabular}

Berdasarkan tabel 1, sampel yang positif menggandung boraks adalah martabak mini dan somai ikan. Hal ini dilihat dari perubahan warna nyala api dari oren kemerahan menjadi hijau. Sampel yang tidak mengandung boraks yaitu mie goreng, martabak kering, kentang bulat. Uji nyala pada sampel dibandingkan dengan blanko, pembanding, dan kontrol. Sampel yang positif boraks selanjutnya dilakukan pengukuran kadar boraks dengan menggunakan Spektrofotometer pada panjang gelombang $541 \mathrm{~nm}$.

\section{Tabel 4.2 Hasil Penelitian Uji Kuantitatif dengan Spektrofotometri UV-Vis}

\begin{tabular}{llc}
\hline No & \multicolumn{1}{c}{ Sampel } & Rata-Rata Konsentrasi (ppm) \\
\hline 1. & Martabak mini & 3,2272 \\
2. & Somai ikan & 2,2356 \\
\hline
\end{tabular}

Boraks pada awal mulanya dikenal sebagai bahan antiseptik yang digunakan sebagai pengawet kayu, pembersih, dan herbisida namun sekarang banyak digunakan sebagai bahan tambahan makanan oleh para pedagang makanan. Absorbsi boraks secara berulang atau berlebihan dapat menimbulkan keracunan. Makanan atau jajanan yang mengandung boraks apabila dikonsumsi tidak berdampak buruk secara langsung terhadap kesehatan tetapi secara kumulatif akan menumpuk sedikit demi sedikit di dalam tubuh. Gejala awal keracunan boraks dapat berlangsung beberapa jam hingga seminggu. Gejala klinis keracunan ditandai dengan sakit perut sebelah atas, muntah, mencret, sakit kepala, penyakit kulit berat, sesak nafas, dan kegagalan sirkulasi darah, tidak nafsu makan, dehidrasi, koma, dan jika berlangsung terusmenerus, maka dapat mengakibatkan kematian (Erniati, 2017).

Pada penelitian ini peneliti menggunakan 5 sampel jajanan anak yang dijual di sekitar SDN 18 dan 20 kota Pekanbaru yang beralamat di Jl. Kulim No.73 Kp. Baru, Senapelan, Kota Pekanbaru. Sampel 
yang diuji dengan nyala api terdapat 2 sampel jajanan anak yang positif yaitu martabak mini dan somai ikan, hal ini dapat dilihat dari perubahan warna uji nyala api yaitu sampel yang positif akan menimbulkan warna nyala api kehijauan yang menandakan adanya boraks pada sampel jajanan tersebut. Sampel yang mengandung boraks akan menunjukkan nyala hijau yang disebabkan oleh terbentuknya metil borat $\mathrm{B}\left(\mathrm{OCH}_{3}\right)$ (Issulaningtyas dan Swandari (2016). Kandungan boraks pada sampel menunjukkan hasil positif pada uji nyala diukur menggunakan metode spektrofotometri.

Penggunaan boraks sebagai bahan pengawet pada makanan dapat digantikan dengan bahan alami. Salah satunya adalah karagenan. Karagenan merupakan terbuat dari rumput laut (Euchena $s p$ ) dan aman untuk dikonsumsi. Bentuk karagenan seperti tepung agar-agar dan sudah banyak dijual di pasarpasar. Harga karegenan memang sedikit lebih mahal jika dibandingkan dengan boraks. Walaupun demikian tetap saja para pedagang makanan dan jajanan di sekitar sekolah dasar tidak boleh menggunakan boraks karena berbahaya bagi kesehatan konsumen sesuai dengan ketentuan yang telah diatur dalam Permenkes RI No.1168/Menkes/Per/X/1999 (Tubagus., dkk, 2013).

Makin baik sikap pedagang pada proses pembuatan jajanan dengan tidak menggunakan boraks, maka makin kecil kemungkinan terjadinya pencemaran boraks pada jajanan yang dijual khususnya di sekitar lingkungan sekolah dasar. Mujianto, dkk., (2005) menyebutkan ada hubungan yang signifikan antara sikap pedagang dengan penggunaan boraks. Sikap merupakan faktor risiko perilaku penggunaan boraks. Sikap pedagang bakso di Kota Bengkulu, 92,5\% termasuk kategori baik sehingga tidak ada penambahan boraks dalam bakso yang mereka jual. Keamanan pangan bergantung pada perilaku manusia. Perilaku bersifat sangat kompleks, tidak hanya pengetahuan yang memengaruhi perilaku seseorang dan dapat ditingkatkan melalui pendidikan tentang keamanan pangan melalui kegiatan-kegiatan penyuluhan (Istiqomah, 2016).

\section{KESIMPULAN}

Berdasarkan uji nyala api sampel yang positif mengandung boraks adalah martabak mini dan somai ikan. Kadar boraks pada sampel martabak mini yaitu sebesar 3,2272 ppm. Kadar boraks pada sampel somai ikan yaitu sebesar 2,2356 ppm

\section{UCAPAN TERIMAKASIH}

Peneliti mengucapkan terimakasih kepada Universitas Abdurrab dan seluruh pihak yang telah membantu dimulai dari proses penelitian hingga penerbitan artikel ini.

\section{DAFTAR PUSTAKA}

Erniati. 2017. Tingkat Pendidikan, Pengetahuan, Sikap Pedagang Bakso dan Penggunaan Boraks Pada Bakso di SDN Lemahputro III Sidoarjo. Jurnal Kesehatan Lingkungan. Vol 9, No.2.

Hidayat, Y dan Muharrami L. K. 2014. Kecendrungan Pilihan Jajanan Pangan Anak SD Terhadap Jajanan Berformalin. Jurnal Pena Sains. Vol 1, No 2.

Issusilaningtyas dan Swandari. 2016. Analisis Kandungan Boraks Sebagai Zat Pengawet Pada Jajanan Bakso. Jurnal Kesehatan Al-Irsyad. Vol 9, No. 1.

Istiqomah, S., Sudarwanto, M. B., dan Sudarnika, E. 2016. Penambahan Boraks Dalam Bakso dan Faktor Pendorong Penggunaannya Bagi Pedagang Bakso Di Kota Bengkulu. Jurnal Sain Veteriner. Vol 34, No 1.

Mujianto, B., Purba, A. V., Widada, N. S., dan Martini, R. 2005. Faktor-faktor yang Mempengaruhi Penggunaan Boraks di Kecamatan Pondok Gede-Bekasi. Buletin Penelitian Kesehatan. Vol 33, No.4.

Peraturan Pemerintah No. 28 tahun 2004: tentang keamanan, mutu, dan gizi pangan (diunduh Januari 2018). Tersedia dari: http://perundangan.pertanian. go.id/admin/p_pemerintah/PP-2804.pdf.

Sultan, P., Saifuddin S., dan Ulfa N. 2013. Analisis Kandungan Zat Pengawet Boraks Pada Jajanan Bakso Di SDN 
Kompleks Mangkura Kota Makassar. MKMI. Vol 13.

Triastuti, E., Fatmawali., dan Max R. J. R. 2013. Analisis Boraks Pada Tahu Yang Diproduksi Di Kota Manado. Pharmacon. Vol 2, No 1.

Tubagus, I., Gayatri C., dan Fatmawali. 2013. Identifikasi Dan Penetapan Kadar Boraks Dalam Bakso Jajanan Di Kota Manado. Pharmacon. Vol 2, No 4. 